\title{
Evaluating Performance Indicators on Mass Transportation Systems in Taipei City--- Application of AHP with Data Envelopment Analysis (DEA) on Bus Systems
}

\author{
How-Ming Shieh \\ Department of Civil Engineering and Information Management, National Central University. Chung- \\ Li. Taiwan, R.O.C. Tel: 886-3-4267254: FAX: 886-3-4254604 \\ Long-Chuang Wang \\ Department of Civil Engineering, Division of Transportation Engineering, National Central \\ University, Chung-Li, Taiwan, R.O.C.
}

\begin{abstract}
The primary purpose of the study is to assess relative operators' performance of mass transportation systems to facilitate a basis for government subsidies. In the study, performance indicators are divided into two major categories: one is the absolute performance indicator and the other is the relative performance indicator. However, the absolute performance indicators may not be able to fully satisfy the needs of government agencies because of their complexity, unfaimess and likely subjectivism. The study employs data envelopment analysis (DEA) associated with analytic hierarchy processes (AHP) to consistently collect the viewpoints of government agencies, operators, users and experts. As the result, representative relative performance indicators are built up, and their values by system are compared. The operators' relative performance indicators can then be evaluated. Ten bus operators are selected for the empirical study.
\end{abstract}

Keywords: Data envelopment analysis, Analytic hierarchy processes, Mass transportation system, Performance indicator

\section{Introduction}

Global economic recession in recent years has driven the government in Taiwan area to reevaluate its subsidy strategies mainly for public faimess and preventing further deterioration of operation, especially on the subsidy to mass transportation systems. Therefore, the primary purpose of the study is to assess reiative operators' performance of mass transportation systems to facilitate a basis for building government subsidy strategies.

In the study, performance indicators are divided into two major categories: one is the absolute performance indicator and the other is the relative performance indicator. The former have been applied traditionally to. integrate users' views on the levels of operators' services for the purpose of providing government agencies with absolute performance indicators instead of predefined performance thresholds. The study employs data envelopment analysis (DEA) associated with analytic hierarchy process (AHP) to consistently collect the viewpoints of government agencies, operators, users and experts. As the result, representative relative performance indicators are built up, and their values by system are compared. The operators' relative performance indicators can then be evaluated. 
Ten bus operators are selected for empirical study. The result may be useful for government agencies to assess the relative performance of mass transportation operators and to further facilitate operators with effective improvement strategies. Afterwards, the result may be employed to assist government agencies with subsidy allocation.

\section{Framework for Building Bus Performance Indicators}

The principal objective of public-owned mass transportation companies is to maximize social welfare instead of pursuing maximal profit. Their performance evaluation therefore emphasizes effectiveness rather than efficiency. On the other hand. the principal objective of private-owned mass transportation companies is to maximize profit. Therefore, they emphasize efficiency instead of effectiveness. On the basis of the concept, it is proposed that performance evaluation for bus systems, including public- and private-owned companies, has to incorporate both efficiency and effectiveness dimensions.

\subsection{Performance Indicators for Bus Systems}

In general, the efficiency and effectiveness are two principal performance indicators for evaluating bus systems: ([3]-[11]) However, interpretation of the two indicators are different. According to Fielding [3], efficiency stands for the degree of resource utilization; and effectiveness stands for the number of served passengers and community demand for the bus service. Mc. Crosson relates efficiency and effectiveness to production and consumption respectively. [3] U.S. Department of Transportation proposes that efficiency be the utilization of labor, capital and resources and effectiveness be the levels towards accomplishing objectives. Moreover, Dajani brings out that efficiency be the measurement of relationship between input and output, and effectiveness be the measurement of the relationship between the degree of passenger satisfaction and mobility of a community. In summary, efficiency indicates systematic management, and effectiveness attempts to imply geography or product. Concerning the relationship between efficiency and effectiveness, Talley points out that efficient operation has to be reached first and the objectives of effectiveness may then be obtained. [16] Therefore, it may be appropriate to take output/input ratio, or output per unit input, as measurement of efficiency. Input factors may include labor, capital, number of vehicles, amount of energy consumption; and output factors may include seat-miles, vehicle-miles, vehicle-time, number of vehicles dispatched. It is also appropriate to take effectiveness as output utilization by a community, for example, fare, passenger-miles and vehicle utilization.

Operational performance for mass transportation systems can be divided into two major categories, i.e. absolute and relative performance indicators, as exhibited in Figure 1. The former is the traditional evaluation model for operators to assess operation of various departments. Nonetheless, it does not satisfy monitors' requirements, i.e. fairness, objectivity and simplicity. On the other hand, the latter 
satisfies the requirements and may guide operators' improvement strategy. The relative performance indicators may be used in two situations. One is for performance comparison among peers; the other is for temporal performance comparison of a company itself. However, it should be careful that the scale fluctuation of a company have to be smail in the study period.

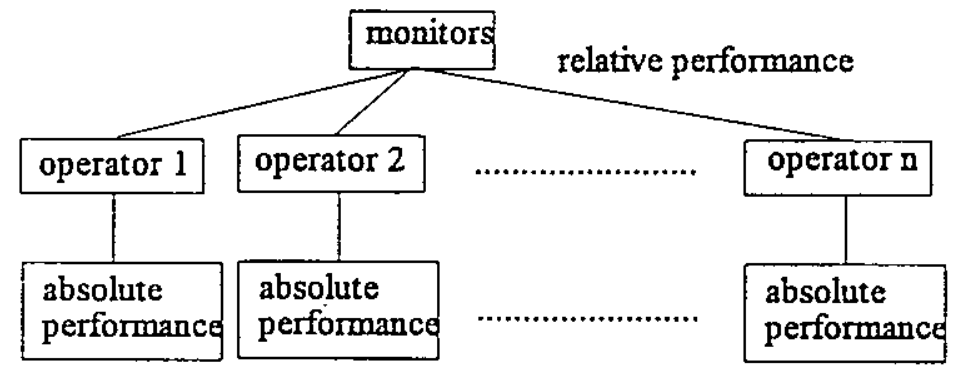

Figure 1. Conceptual Diagram of Performance for Bus Systems

\subsection{Guidelines for building performance indicators}

To build objective performance indicators, a set of guidelines is proposed.

1. Mandated properties of ideal performance indicators

(1) tightly correlated to the objectives of bus operation

(2) quantitative

(3) completed

(4) not repetitive

(5) data obtainable

(6) a small set of indicators

(7) temporal

2. The endogenous variables have to incorporate the three dimensions: service, economy and efficiency.

3. To possess objectivity and all-inclusive, it is better to incorporate the viewpoints of monitors, operators, users and experts and scholars.

\subsection{Framework of Evaluation Models}

As exhibited in Figure 2, quarterly (or yearly) statistical data for bus systems are collected and used as input to efficiency and effectiveness models, which are calibrated by AHP. Consulting monitors, operators, users, and experts and scholars, the weights for the two models are obtained. The computed results using the collected data are then directed to DEA (data envelopment analysis) evaluation model which may compute relative performance measures among peers. 


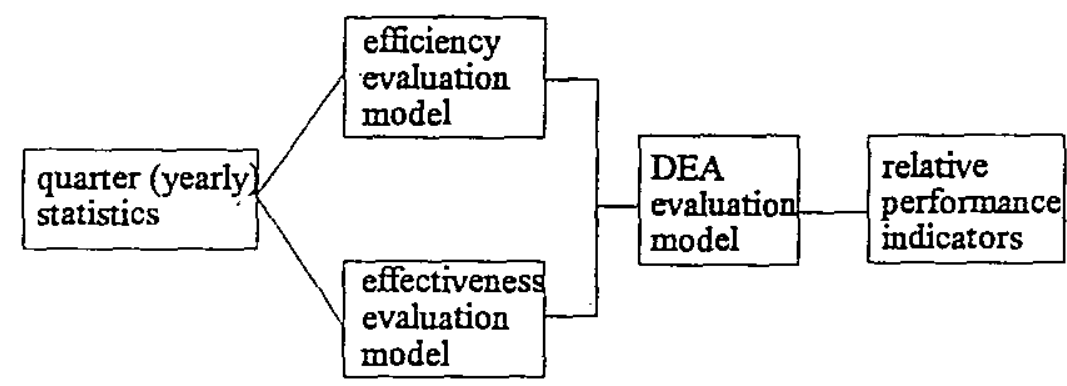

Figure 2. Framework of Evaluation Models

\subsection{Building Absolute Bus Performance Indicators}

The hierarchy structure for evaluating performance of bus operation is exhibited as Figures 3 and 4 based on efficiency and effectiveness. ([5]-[11])

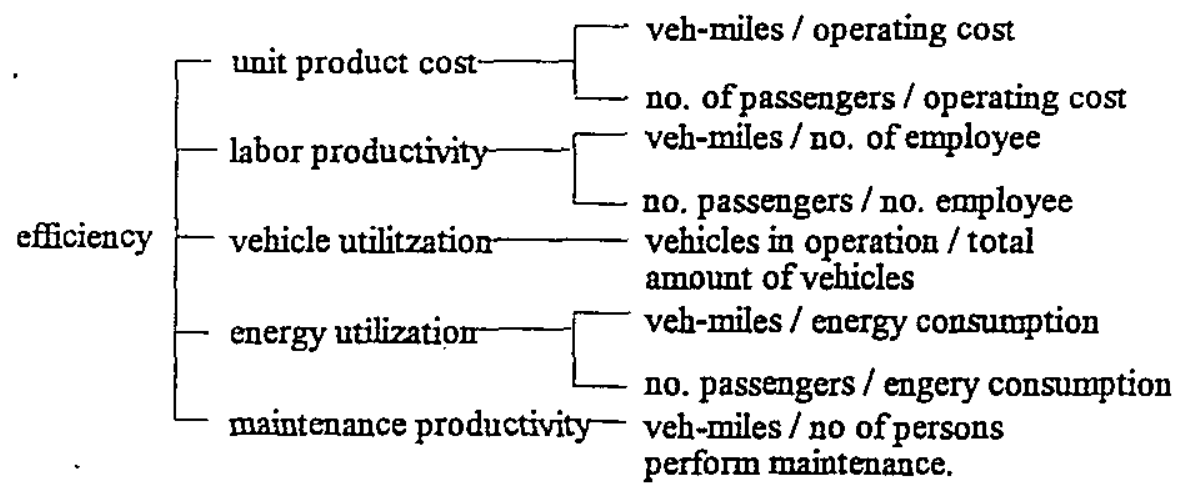

Figure 3. Hierarchy Structure for Evaluating Efficiency

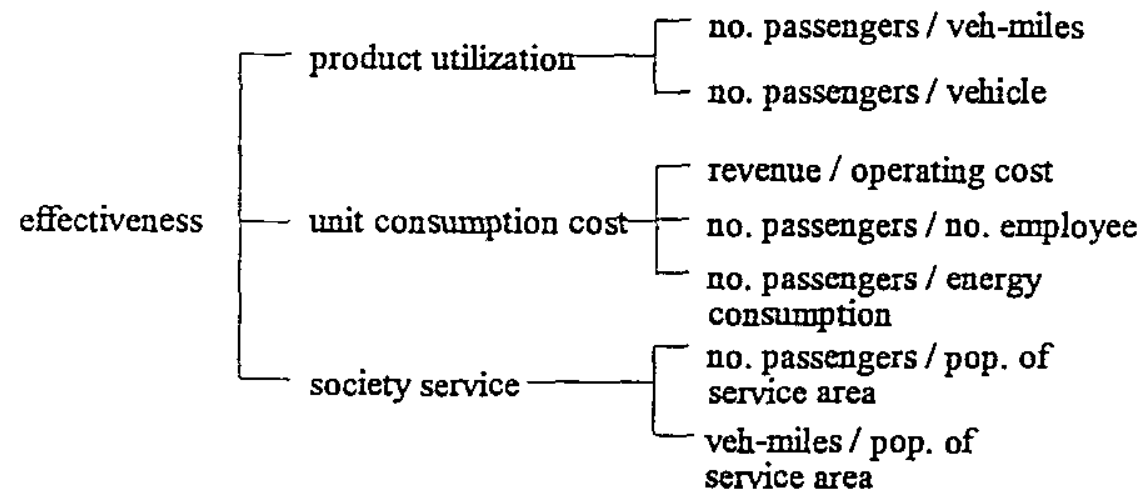

Figure 4. Hierarchy Structure for Evahuating Effectiveness 


\subsection{Building Relative Bus Performance Indicators}

The relative performance indicators for bus systems are manipulated by data envelopment analysis (DEA), which was initially proposed by Farrell in 1957 to measure efficiency for production department using a unique output variable based on Pareto optimality. However, DEA has got extensive attention since Chames Cooper and Rhodes proposed multivariate DEA models in 1978. Chu and Fielding [3] applied the DEA on mass transportation systems to evaluate their operational performance.

One of the major advantage of DEA is to measure relative performance among peers. The DEA assumes consistent economy of scale among peers with crosssectional data, defines appropriate variables with selective input-output ratios, perform mapping to coordinate space, seek for performance frontier of extreme values, connect the frontiers to obtain the edge of optimal performance, and exhibit results by explicit proportion with data envelopment concept. The monitor may then be able to understand operators' relative performance.

The major characteristics of DEA may be stated as follows:

1. It employs a single ratio to represent a decision making unit (DMU) for input-output relationship, that the magnitude a DMU stands for efficiency.

2. It compares relative performance of DMUs.

3. Synthesize various input-output relations without prior weighting.

4. It takes qualitative factors into account.

5. It provides the magnitude of increment required to reach an accessible degree of efficiency.

However, following limitation may be expected for employing DEA:

1. The collected data have to be accurate for DEA's not taking random errors into account.

2. It assumes constant economy of scale and linear production function.

\section{Empirical Study}

The data are collected from the ten bus operators in Taipei city. Two of the ten bus operators are public-owned, i.e. $A_{1}$ and $A_{2}$. The remaining are private-owned, i.e. $A_{3}-A_{10}$. In addition, ten members of the group decision makers $\left(D M_{1}-D M_{10}\right)$, including monitors, operators, users, and experts and scholars, are consulted to perform pairwise comparison to determine the weights for performance indicators. The results are shown in Table 1 and 2. 
Table 1

Order of Efficiency Indices for Operators by Ten Group Decision-Makers

\begin{tabular}{cccccccccccc}
\hline $\begin{array}{c}\text { Decision- } \\
\text { makers }\end{array}$ & \multicolumn{10}{c}{ Operators } \\
\cline { 2 - 13 } & A1 & A2 & A3 & A4 & A5 & A6 & A7 & A8 & A9 & A10 \\
\hline DM1 & 10 & 4 & 8 & 3 & 7 & 1 & 5 & 2 & 9 & 6 \\
DM2 & 10 & 3 & 8 & 2 & 7 & 4 & 5 & 1 & 9 & 6 \\
DM3 & 10 & 3 & 6 & 2 & 8 & 4 & 5 & 1 & 9 & 7 \\
DM4 & 10 & 3 & 8 & 2 & 7 & 4 & 5 & 1 & 9 & 6 \\
DM5 & 10 & 3 & 8 & 2 & 7 & 4 & 5 & 1 & 9 & 6 \\
DM6 & 10 & 3 & 6 & 2 & 8 & 4 & 5 & 1 & 9 & 7 \\
DM7 & 10 & 3 & 6 & 2 & 8 & 4 & 5 & 1 & 9 & 7 \\
DM8 & 10 & 3 & 8 & 2 & 7 & 4 & 5 & 1 & 9 & 6 \\
DM9 & 10 & 3 & 6 & 2 & 8 & 4 & 5 & 1 & 9 & 7 \\
DM10 & 10 & 3 & 8 & 2 & 7 & 4 & 5 & 1 & 9 & 6 \\
\hline
\end{tabular}

Table 2

Order of Effectiveness Indices for Operators by Ten Group Decision-Makers

\begin{tabular}{|c|c|c|c|c|c|c|c|c|c|c|}
\hline \multirow{2}{*}{$\begin{array}{c}\text { Decision- } \\
\text { makers }\end{array}$} & \multicolumn{10}{|c|}{ Operators } \\
\hline & $\mathrm{Al}$ & A2 & $\mathrm{A3}$ & $\mathrm{A4}$ & A5 & A6 & A7 & A8 & A9 & $\mathrm{Al0}$ \\
\hline DM1 & 4 & 2 & 10 & 7 & 6 & 9 & 8 & 1 & 3 & 5 \\
\hline DM2 & 4 & 2 & 10 & 7 & 6 & 9 & 8 & 1 & 3 & 5 \\
\hline DM3 & 4 & 2 & 10 & 7 & 6 & 9 & 8 & 1 & 3 & 5 \\
\hline DM4 & 4 & 2 & 10 & 7 & 6 & 9 & 8 & 1 & 3 & 5 \\
\hline DM5 & 4 & 2 & 10 & 7 & 6. & 9 & 8 & 1 & 3 & 5 \\
\hline DM6 & 4 & 2 & 10 & 7 & 6 & 9 & 8 & 1 & 3 & 5 \\
\hline DM7 & 4 & 2 & 10 & 7 & 6 & 9 & 8 & 1 & 3 & 5 \\
\hline DM8 & 4 & 2 & 10 & 7 & 6 & 9 & .8 & 1 & 3 & 5 \\
\hline DM9 & 4 & 2 & 10 & 7 & 6 & 9 & 8 & I & 3 & 5 \\
\hline DM10 & 4 & 2 & 10 & 7 & 6 & 9 & 8. & 1 & 3 & 5 \\
\hline
\end{tabular}

\subsection{Application of ABP}

Based on the aforementioned efficiency and effectiveness hierarchy structure (Figure 3 and 4) associated with the collected data from consulting the monitors, operators, users, and experts and scholars, the calibrated models are shown below:

$$
\begin{aligned}
\text { efficiency index } & =0.290 * \text { unit product cost } \\
& +0.226^{*} \text { labor productivity } \\
& +0.226^{*} \text { vehicle utilization } \\
& +0.161 * \text { energy utilization } \\
& +0.097 * \text { maintenance productivity }
\end{aligned}
$$




$$
\begin{aligned}
\text { effectiveness index } & =0.456 * \text { product utilization } \\
& +0.171 * \text { unit consumption cost } \\
& +0.373 * \text { society service }
\end{aligned}
$$

\subsection{Application of DEA}

The weights obtained from AHP are then used to compute the two performance indicators, efficiency and effectiveness for the ten bus companies in Taipei city. The maximum is assumed to be 1.0 and is used to compute the two relative performance indicators for the ten bus companies, of which two of them are public-owned. The: result is exhibited as Figure 5.

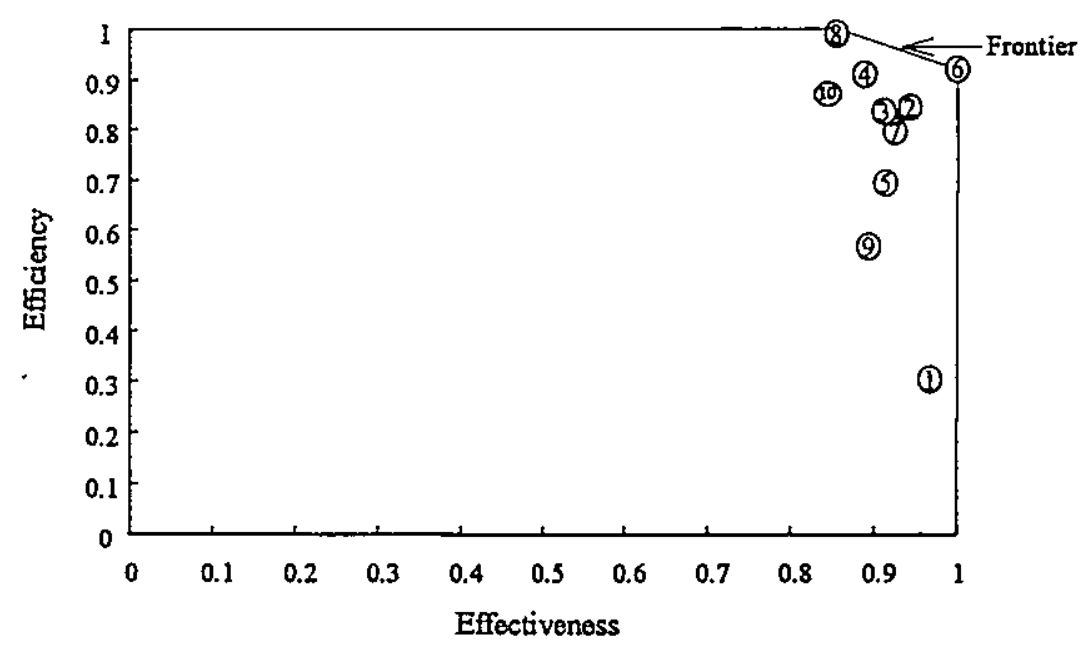

Figure 5. DEA Result of The Two Relative Performance Indicators

\section{Conclusions and Suggestions}

Grenerally speaking, the study emphasizes on the concept of relative performance. Applying AHP to synthesize viewpoints of monitors, operators, users and domain expert and scholars, we build a set of simple, objective, extensive and representative performance indicators in terms of efficiency and effectiveness. In combination with DEA, the results show that the operation of private bus companies is better than public bus companies in terms of efficiency. But in terms of effectiveness, the results are slightly different since public bus companies have more resources to use than private bus companies.

It is suggested that the absolute performance measures of the bus company with best relative performance among peers obtained from DEA be used to guide the improvement for the bus companies with the less efficient operation. For the same bus company, same inference mechanism can be referred. 
In the near future, mass transit systems will be established in six metropolitan areas along the western corridor in Taiwan. With the huge investment and professionalism, operational management and its improvement measures become complicated. The study would provide an experience of evaluating absolute and relative performance for prospective monitors and operators to reference.

\section{References}

[1] Chang K.P. and Y.Y. Guh, "Linear production functions and the Data Envelopment Analysis", European Journal of Operational Research, 52/2 (1991), 215-223.

[2] Chang K.P and P.H. Kao, "The relative efficiency of public versus private manicipal bus firms : An Application of Data Envelopment Analysis", The Journal of Productivity Analysis 3 (1992) 67-84.

[3] Chu X. and G.J Fielding, "Measuring transit performance using Data Envelopment Analysis", Transoprtation Research-A 26/3(1992) 223-230.

[4] Dajani J.S. and Gilbert G., "Measuring the performance of transit systems", Transpn. Plann. Technol. 4/2 (1978) 97-103.

[5] Fielding G.J. and Glauthier RE. and Lave C.A., "Performance indicators for transit management", Transportation 7/4 (1978) 365-379.

[6] Fielding G.J. and Mundle S.R and Misner J., "Performance based funding allocation guidelines for transit operations in Los Angeles county", Transportation Research Record, 857, 1982, 14-18.

[7] Fielding G.J. and Anderson S.C., "Public transit performance evaluation : Application to selection 15 data", Transportation Research Record, 947, 1983, 1-7.

[8] Fielding G.J. and Babitsky T.T. and Brenner M.E., "Performance analysis for bus transit", Transoprtation Research-A $19 / 1$ (1985) 73-82.

[9] Fielding G.J. and Brenner M.E. and Faust K., "Typology for bus transit", Transoprtation Research-A 19/3 (1985) 269-278.

[10] Fielding G.J., Managing Public Transit Strategically, Jossey-Bass; San Francisco, CA., 1987.

[11] Fielding G.J. and Hanson L., "Determinants of superior performance in public transit : Research opportunities using Section 15 data", Transportation Research Record 1165, 1988, 94-98.

[12] Golany B. and Y.Roll, "An application procedure for DEA", International Journal of Management Science, 17/3 (1989) 237-250.

[13] Hatry H.P, "Performance measurement principles and techniques : An overview for local government", Public Productivity Review 4 (1980) 312-339.

[14] Lee D., "Transit cost and performance measurement", Transport Reviews, 9/2(1989) 147-170.

[15] Sexton T.R, "The methodology of data envelopment analysis" In: R.H.Silkman(ed.), Managinfg Efficiency : An Assessment of Data Envelopment Analysis, Ossey-Bass Inc., San Francisco, 1986, 7-30.

[16] Talley W.K.Becker J., "A single measure for evaluating public transit systems", Transportation Quarterly 36/3 (1982) 423-431. 
[17] Talley W.K.and Anderson P.P, "Effectiveness and Efficiency in Transit Performance : A Theoretical Perspective", Transoprtation Research-A 15/6 (1981) 431- 436.

[18] U.S. Department of Transportation, Urban Mass Transportation Administration, "National Urban Mass Transportation Statistics", 1986 Section 15 Report, U.S. Goverment Printing Office (UMTA-VA-06-0127-88-1), Washington, D.C., 1988.

[19] Zerrills R.J. and Keck C.A. and Schneider N.R, "Analysis of Transit Performance Measures Used in New York State", Transportation Research Record 797, 1981, 52-58. 